\title{
Capacity Building for Global Food Security through Digital Agricultural Technology Enhancement
}

\author{
Ganesh Bora* \\ Department of Agricultural and Biological Engineering, Mississippi State University, USA \\ *Corresponding author: Ganesh Bora, Department of Agricultural and Biological Engineering, Mississippi State University, USA
}

\section{Mini Review}

Among the 17Sustainable Development Goals (SDG) of the United Nations Development Program (UNDP), the goal 2 is "Zero Hunger". An estimated 821 million of 7.53 billion on the earth were undernourished in 2017. The majority of the world's hungry people live in developing countries, where 12.9 per cent of the population is undernourished. It is a fact that people across the globe, rural and urban, poor and rich, should have access to adequate amount of food and nutrition to maintain an active and healthy life.

Earlier green revolution was focused on high yielding variety and genetic engineering of crops. But future steps towards achieving global food security will be depended on adaptation of technology by farmers. The policy makers along with scientists, academicians, youth and progressive farmers have substantial influence on country specific development of modern agricultural technologies required for increased food productivity. Food security in developing countries can be achieved by sustainable increase in crop yield as well as reducing post-harvest losses with help of technologies. Also, food diversity plays an important role to meet the necessary nutrition levels alongside food quantity and quality.

Digital Agricultural technology has greatly optimized the use of inputs in developed countries and it has positive economic \& environmental impact with increase in crop yield. Similar technology may not work in developing countries but the concept behind the technology would work. Transfer of concept, not transfer of technology, is key to successful global adaptation of precision agricultural technology to optimize resources for sustainable global crop production and food security. When the concept works for the particular crop or in a region; the technology can be developed locally. Adaptation of concept of technology is further depended on social inequality and regional instability. The workforce development is necessary to adapt to the concept and develop the technology locally with readily available materials in that area (Figure 1).

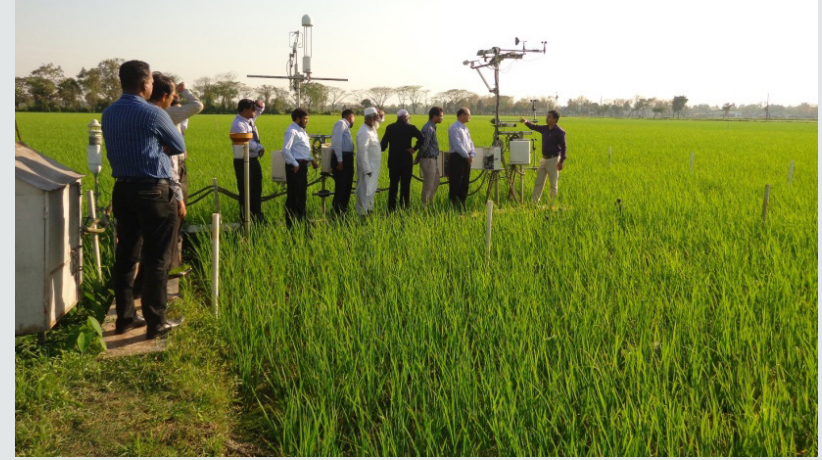

Figure 1: Workshop for capacity building to adapt precision agricultural technology in Bangladesh. 
Developing work for ceto enhance the capacity of adapting digital agricultural technology to increase crop production will not only guarantee food security but also help in mitigating climate change, especially reducing greenhouse gas emission by variable rate application of fertilizer, chemicals and water in crop field. The farmers who understand and continue to use technology will be able to grow more food to provide better nutrition. On the contrary, who would not use technology, may have difficult times ahead. Adaption of technology will prepare us for nourishing the global population. To prepare for the future, I am reminded of the quote from Charles Darwin, "It is not the strongest of the species that survives, nor the most intelligent that survives. It is the one that is most adaptable to changes".

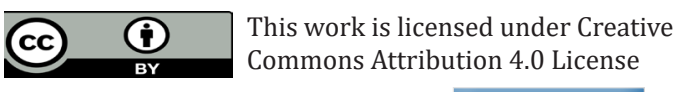

To Submit Your Article Click Here: Submit Article

DOI: $10.32474 /$ CIACR.2020.08.000294

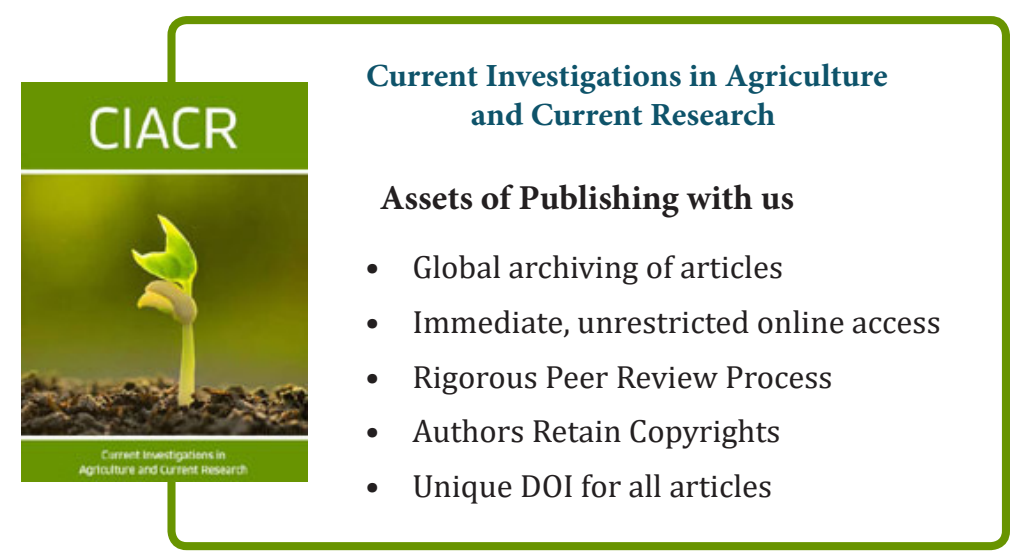

